\title{
Research competency guidelines for literatures in English \\ A draft
}

\author{
by the ACRL Literatures in English Section Ad hoc Committee on Literary Research \\ Competencies
}

\section{Purpose of the guidelines}

- To aid students of literatures in English in the development of thorough and productive research skills;

- to encourage the development of a common language for librarians, faculty, and students involved with research related to literatures in English;

- to encourage librarian and faculty collaboration in the teaching of research methods to students of literatures in English;

- to aid librarians and faculty in the development of research methods courses at the undergraduate and graduate levels.

Because teaching methods, course content, and undergraduate requirements vary by institution, librarians and faculty may apply these guidelines in different ways to meet the needs of their students. ${ }^{1}$

\section{Outcomes for undergraduate English or American Literature majors I. Understand the structure of infor- mation within the eld of literary re- search}

A. Differentiate between primary and secondary sources and use each appropriately.

B. Understand that literary scholarship is produced and disseminated in a variety of formats, including monographs, journal articles, conference proceedings, dissertations, reference sources, and Web sites.

C. Learn the significant features (e.g., series title, volume number, imprint) of different kinds of documents (e.g., journal articles, monographs, essays from edited collections) before beginning research or attempting to apply citation style formats.

D. Differentiate between reviews of literary works and literary criticism.

E. Understand the concept of peer reviewed sources of information.

F. Understand that literary texts exist in a variety of editions, some of which are more authoritative or useful than others.

G. Understand the process of literary production, from authors' manuscripts through publication, in a variety of printed editions and formats and including availability in bookstores, libraries, and on the Internet.

\section{Identify and use key literary research tools to locate relevant information}

A. Effectively use library catalogs to identify relevant holdings at local institutions and use print and online catalogs and bibliographic tools to identify holdings at other libraries.

B. Distinguish among the different types of reference works (e.g., bibliographies of bibliographies, annals, serial bibliographies, abstracts, literary dictionaries) and understand the kind of access to information offered by each.

C. Identify, locate, evaluate, and use reference information about authors, critics, and theorists.

D. Use subjective and objective sources, such as book reviews and citation indexes, to determine the relative importance of an 
author and/or specific work.

E. Use reference resources to provide background information and contextual information about social, intellectual, and literary culture.

F. Understand the range of physical locations in one's local library system and the local retrieval and delivery services available.

G. Understand the uses of consortia catalogs and services.

\section{Plan effective search strategies and modify search strategies as needed}

A. Use appropriate commands (such as Boolean operators) for database searches.

B. Identify broader, narrower, and related terms or concepts when initial searches retrieve few or no results.

C. Identify and use subject terms from the MLA International Bibliography and other specialized indexes and bibliographies.
D. Identify and use Library of Congress subject headings for literature and authors.

IV. Recognize and make appropriate use of library services in the research process:

A. Identify and use librarians and reference services in the research process.

B. Use interlibrary loan and document delivery to acquire materials not available at one's own library.

C. Use digital resource service centers to read and create literary and critical documents in a variety of digital forms.

\section{Understand that some information sources are more authoritative than oth- ers and demonstrate critical thinking in the research process}

A. Learn the different types of Internet

\section{Development of the Guidelines}

"Research competency guidelines for literatures in English" were first developed for use within ACRL's Literature in English Section (LES). Although based on the framework of the "Information literacy competency standards for higher education," these guidelines address the need for a more specific and source-oriented approach within the discipline of English literatures, with a concrete list of research skills.

The original list was compiled by Anne Jordan Baker (Elmhurst College).The draft guidelines were posted to the LES-L group for comments on December 10, 2001.A revision based on those comments was discussed at the 2002 ALA Midwinter Meeting. The guidelines were also published in "Biblio Notes," the LES newsletter, and readers were encouraged to submit comments.A draft based on all information and comments to date was posted to the LES-L group for further review on April 12, 2002.

A final draft was presented at the 2002 ALA Annual Conference and was approved by the Literatures in English Executive Committee.

\section{LES Ad hoc Committee on Literary Research Competencies}

Heather Martin, University of Alabama-Birmingham

Austin Booth, University at Buffalo-SUNY

Charlotte Droll, Wright State University

Louise Greenfield, University of Arizona

Anne Jordan Baker, Elmhurst College

Jeanne Pavy, University of New Orleans

Judy Reynolds, San Jose State University

Comments on this proposed guideline should be sent to:Kathleen Kluegel,English Librarian, University of Illinois at Urbana Champaign, 1408 W. Gregory Drive, Urbana, IL 61801, E-mail:kkluegel@uiuc.edu

A hearing on the guidelines will be held at the ALA Midwinter Meeting in Boston, Saturday, January 15, from 2:00-3:00 p.m. 
resources (e.g., electronic discussion lists, Web sites) and how to evaluate them for relevancy and credibility.

B. Differentiate between resources provided free on the Internet and other electronic resources.

VI. Understand the technical and ethical issues involved in writing research essays

A. Employ the MLA documentation style and document sources ethically.

B. Understand the relationship between received knowledge and the production of new knowledge in the discipline of literary studies.

C. Analyze and ethically incorporate the work of others to create new knowledge.
VII. Locate information about the literary profession itself

A. Access information about graduate programs; specialized programs in film study, creative writing, and other related fields; and workshops and summer study opportunities.

B. Access information about financial assistance and scholarships available for literary study and related fields.

C. Access information on careers in literary studies.

\section{Note}

1. For guidelines on helping students develop general research skills, librarians and faculty may refer to the "Information literacy competency standards for higher education" at www.ala.org/ala/acrl/acrlstandards/informationliteracycompetency.htm. $\mathbf{z}$

\section{Elegant Solutions for Preservation}

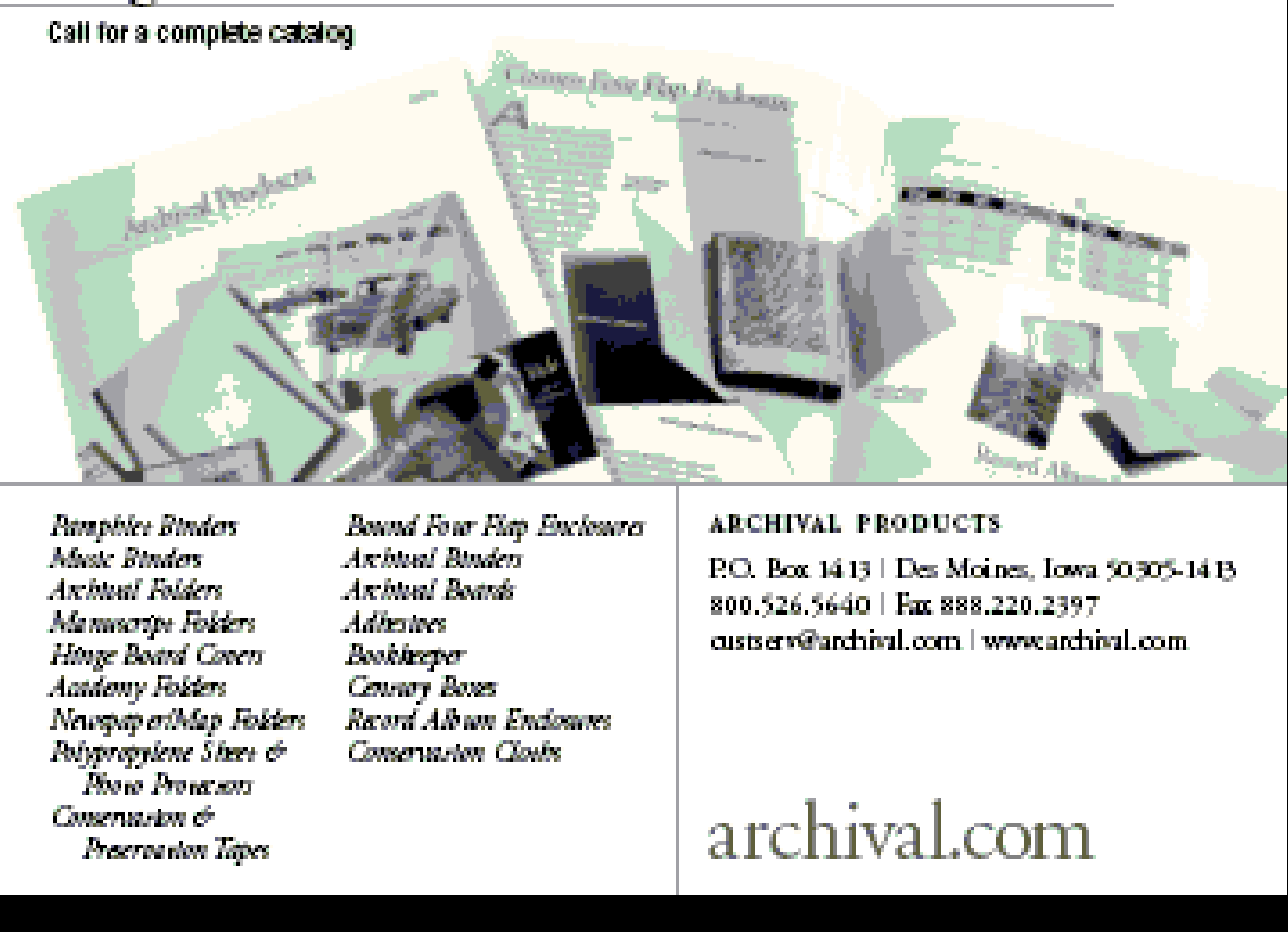

